American Journal of Biochemistry and Biotechnology 4(3): 277-278, 2008

ISSN 1553-3468

(C) 2008 Science Publications

\title{
Essential Oil Component in Flower of Lemon Balm (Melissa officinalis L.)
}

\author{
Jafer Adinee, Khosro Piri and Omid Karami \\ Department of Biotechnology, \\ Faculty of Agriculture, Bu-Ali Sina University, Hamedan, Iran
}

\begin{abstract}
This research focuses on the analysis of the chemical composition lemon balm essential oil. The essential oil of flowers was obtained by steam distillation with a Clevenger apparatus. The chemical components of the essential oil of lemon balm were analyzed by capillary GC and GC/MS and 12 substances were identified. The flower oil contained trans-carveol (28.89\%), citronellol $(25.24 \%), \delta$-3-carene $(5.26 \%)$, citronellal $(4.9 \%)$, geraniol $(2.2 \%)$, 1-octene-3-ol $(2.03 \%)$ and spathulenol $(2.06 \%)$. The trans-carveol in flowers was dominant among components.
\end{abstract}

Keywords: Lemon balm, essential oil, GC-MS

\section{INTRODUCTION}

Lemon balm (Melissa officinalis L.), a member of Laminaceae, is a perennial plant growing up to $100 \mathrm{~cm}$. This species originates from southern Europe, Asia Minor and southern parts of North America. Lemon balm populations are distributed in all Mediterranean countries including the coastal regions of Turkey and northern $\operatorname{Iran}^{[6]}$.

Lemon balm is used for several purposes such as an additive in food, a herb tea, an ingredient in cosmetics, an ornamental and a medicine ${ }^{[8]}$. s essential oil is currently used in medicine and pharmacology (anti-tumor, anti-bacterial, antimicrobial, antihistaminic, antispasmodic and antioxidant, by means of its antiviral effect curing of the herpes ${ }^{[1]}$, antiulcerogenic, moderate Alzheimer's disease, modulation of mood and cognitive performance, stimulating the immune system (against anti HIV-1) ${ }^{[12]}$. In addition, lemon balm has traditionally been used due to its memory enhancing properties, but using of which is currently more widely used as sedative or calm, spasmolytic and antibacterial agent and sleep aid has been more popular recently ${ }^{[2,5,7]}$.

The goal of the present work was to study the composition and content of the essential oil of lemon balm. The composition of these oils may be useful in the identification of aromatic compounds of lemon oil obtained commercially by steam distillation.

\section{MATERIALS AND METHODS}

Plant material: The lemon plant used in the present study was prepared from Medicinal Plants Garden of
Ebne-Sina at Hamedan of Iran. During summer flowers were collected from field grown plants.

Essential oil extraction: For the isolation of the essential oil, the hydrodistillation method with the use of a Clevenger apparatus was used. The flowers were carefully cleaned and distilled separately for $3 \mathrm{~h}$. Oil samples were over anhydrous sodium sulfate and stored in sealed vial at low temperature before analysis.

GC: GC analysis was performed using a Shimadzu GC -9A gas chromatograph equipped with a DB-1 fused silica column $(60 \mathrm{~m} \times 0.25 \mathrm{~mm}$, film thickness $0.25 \mu \mathrm{m}$ ), oven temperature was help at $40^{\circ} \mathrm{C}$ for $5 \mathrm{~min}$ and then programmed to $250^{\circ} \mathrm{C}$ at a rate of $4^{\circ} \mathrm{C} \mathrm{min}^{-1}$, injector of $32 \mathrm{~cm} \mathrm{sec}^{-1}$. Quantitative data was obtained from FID area percentage without the use of correction factors.

GC/MS: GC/MS analysis was carried out on a Varian 3400 GC/MS system equipped with a DB-1 fused silica column $(60 \mathrm{~m} \times 0.25 \mathrm{~mm}$, film thickness $0.25 \mu \mathrm{m})$. Oven temperature $50-250^{\circ} \mathrm{C}$ at rate of $4^{\circ} \mathrm{C} \mathrm{min}^{-1}$, transfer line temperature $260^{\circ} \mathrm{C}$, carrier gas, helium with a linear velocity of $31.5 \mathrm{~cm} \mathrm{sec}^{-1}$, split ratio $1 / 60$, ionization energy 70 e $\mathrm{V}$, scan time $1 \mathrm{~s}$, mass range $40-$ $300 \mathrm{amu}$.

Identification of components: The components of the oil were identified by comparison of their mass spectra with those of a computer library or with authentic compounds and confirmed by compaction of their

Corresponding Author: Khosro Piri, Department of Biotechnology, Faculty of Agriculture, University Bu-Ali Sina, Hamedans, Iran Tel: +9183163372 Fax: +8114227012 
Table 1: Percentage of lemon balm flower essential oil components

\begin{tabular}{|c|c|c|}
\hline Components & Peak number & $(\%)$ \\
\hline 1-octen-3-ol & 2 & 2.030 \\
\hline$\delta$-3-Cavene & 3 & 5.260 \\
\hline Linalool & 6 & 4.050 \\
\hline Lavendulol & 7 & 0.390 \\
\hline Trans-carveol & 16 & 28.89 \\
\hline Citronellol & 20 & 25.24 \\
\hline Geraniol & 23 & 02.20 \\
\hline$\gamma$-Murolol & 27 & 01.69 \\
\hline Germacrene. D & 28 & 00.49 \\
\hline Spathulenol & 29 & 02.06 \\
\hline a-Cadinol & 30 & 00.16 \\
\hline Trans-Murolol & 31 & 00.36 \\
\hline
\end{tabular}

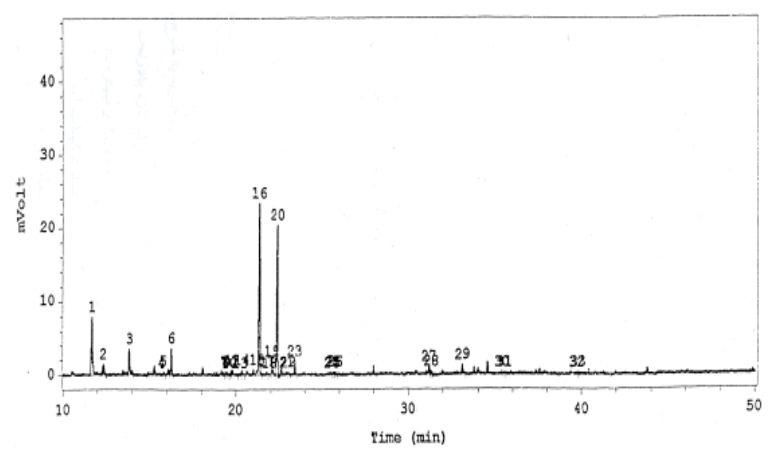

Fig. 1: Chromatogram of lemon flower essential oil

retention indices, either with those of authentic samples or with data published in the literature ${ }^{[4]}$.

\section{RESULTS AND DISCUSSION}

In Fig. 1 the chromatogram of lemon flowers essential oil are presented. The principal components of essential oil of the flowers are presented on Table 1: trans-carveol (28.89\%), citronellol (25.24\%), $\delta$-3carene $(5.26 \%)$, citronellal $(4.9 \%)$, geraniol $(2.2 \%)$, $1-$ octene-3-ol $(2.03 \%)$ and spathulenol $(2.06 \%)$.

The citronellal, citronellol, linalool and geranial as major chemical compositions of the essential oil of the lemon balm has been previously reported, ${ }^{[6,9,10,11]}$, but trans-carveol is not reported as main components of essential oil in lemon. Carveol is a natural monoterpenoid alcohol. It is used as a fragrance in cosmetics and as a flavor additive in the food industry. It has been found to exhibit chemoprevention of mammary carcinogenesis (prevents breast cancer ${ }^{[3]}$ ). Monoterpenes in plants are believed to play ecological roles mainly, serving as herbivore-feeding deterrents, antifungal defenses and attractants for pollinators ${ }^{[13]}$. Their oxidised derivatives, known as terpenoids, are used as flavours, fragrances and pharmaceuticals ${ }^{[13]}$.

\section{REFERENCES}

1. Allahverdiyev, A., N. Duran, M. Ozguven and S. Koltas, 2004. Antiviral activity of the volatile oils of Melissa officinalis L. against herpes simplex virus type-2., Phytomedicine, 11: 657-661.

2. Coleta, M., M.G. Campos, M.D. Cotrim and A. Proenca Cunha, 2001. Comparative evaluation of Melissa officinalis L., Tilia europaea L., Passiflora edulis Sims and Hypericum perforatum $L$. in the elevated plus maze anxiety test. Pharmacopsychiatry, 34: 20-21.

3. Crowell, P.L., H. Kennan and V. Ahmad, 1992. Chemoprevention of mammary carcinogenesis by hydroxylated derivatives of d-limonene. Carcinogenesis, 13:1261-1264.

4. Davis, N.W., 1990. Gas chromatographic retention indices of monoterpenes and sesquiterpenes on methyl silicone and carbowax $20 \mathrm{~m}$ phrases. J. Chromatogr., 503: 1-24.

5. Kennedy, D.O., W. Little and A.B., 2004. Schley, Attenuation of laboratory-induced stress in humans after acute administration of Melissa officinalis (lemon balm). J. Pharm Pharmacol., 56: 677-681.

6. Mrlianova, M., D. Tekelova, M. Felklova, J. Toth, P. Musil and D. Grancai, 2001. Comparison of the quality of Melissa officinalis L. cultivar Citra with Mellissas of European origin. Pharmacospsychiatry, 34: 20-21.

7. Sadraei, H., A. Ghannadi and K. Malekshahi, 2003. Relaxant effect of essential oil of Melissa officinal is and citral on rat ileum contractions. Phytother. Res., 17: 599-604.

8. Sarı, A.O. and A. Ceylan, 2002. Yield characteristics and Essential oil composition of lemon balm (Melissa officinalis L.) grown in the Aegean Region of Turkey. Turk. J. Agric. For., 22: 217-224.

9. Sorensen, J.M., 2000. Melissa officinalis, Essential oil-authenticity, production and pharmacologicalactivit. Int. J. Aromather., 10: 1-8.

10. Tittel, G., H. Wagner and R. Bos, 1982. Chemical composition of the essential oil from Melissa. Planta Med., 46: 91-98.

11. Vaverkova, S., J. Tekel and M. Holla, 1995. The effect of herbicides on the qualitative properties of medicinal plants. Part 3: Content and composition of the essential oil from Melissa officinalis L. after application of basagran. Pharmazie, 50: 835-836.

12. Yamasaki, K., M. Nakano, T. Kawahata, H. Mori, T. Otake, N. Ueba, I. Oishi and R. Inami, M. Yamane, M. Nakamura, H. Murata and T. Nakanishi, 1998. Anti- HIV-1 activity of herbs in Labiatae. Biol. Pharm. Bull., 21: 829-833.

13. Keith Owens, M., L. Chii-Dean, A. Charles, J. Taylor and G. Steven, 1998. whisenant4seasonal patterns of plant flammability and monoterpenoid content in juniperus ashei. J. Chem. Ecol., 24: 2115-2129. 